\title{
Is There a Role for Topical Swallowed Steroids upon Emergency Room Admission for Suspected Food Bolus Obstruction in Eosinophilic Esophagitis?
}

\author{
Philipp Schreiner $^{1}$ (D) $\cdot$ Thomas Greuter $^{1} \cdot$ Aurora Tatu $^{1} \cdot$ Dagmar I. Keller $^{2} \cdot$ Alex Straumann $^{1} \cdot$ Luc Biedermann $^{1}$
}

Received: 19 September 2020 / Accepted: 6 August 2021 / Published online: 16 August 2021

(c) The Author(s) 2021

\begin{abstract}
Since most pharmacological treatments in case of esophageal food impaction (EFI) are unsuccessful, an endoscopy is usually required to resolve EFI. We present the first results of a budesonide orodispersible tablet (BOT) as a medical treatment option before endoscopy. We evaluated all patients with a suspected EFI to receive BOT before emergent endoscopy at a tertiary hospital between March 2019 and June 2020. A total of eight patients received BOT before endoscopy. Mean age was 50.1 years and $87.5 \%$ were male. In $38 \%$ (3/8) of patients the EFI resolved without endoscopic intervention. No adverse events occurred. After endoscopy, a diagnosis of EoE was established in $75 \%$. This case series demonstrate the potential of BOT as medical rescue therapy in case of EFI.
\end{abstract}

Keywords Esophageal food impaction · Budesonide orodispersible tablet $\cdot$ Deglutition $\cdot$ Deglutition disorders

\author{
Abbreviations \\ BOT Budesonide orodispersible tablet formulation \\ EFI Esophageal food impaction \\ EoE Eosinophilic esophagitis \\ ER Emergency room \\ SD Standard deviation \\ STC Swallowed topical corticosteroids
}

\section{Introduction}

Nowadays, eosinophilic esophagitis (EoE) represents the most common cause of esophageal food impaction (EFI) in patients presenting to the emergency room (ER) [1]. Despite conflicting evidence of pharmacological treatment options [2], several drugs have been suggested to avoid the invasive and costly endoscopy in EFI [3, 4].

Philipp Schreiner

philipp.schreiner@usz.ch

1 Department of Gastroenterology and Hepatology, University Hospital Zurich, Raemistrasse 100, 8091 Zurich, Switzerland

2 Emergency Department, University Hospital Zurich, Zurich, Switzerland
Currently, the only approved medication for treatment of EoE is a budesonide orodispersible tablet formulation (BOT, Jorveza () showing high efficacy in induction [5] and in maintenance [6] treatment. Although the onset of action of locally administered glucocorticoids, including swallowed topical steroids (STCs) such as budesonide, in terms of genomic anti-inflammatory effects is typically within hours [7], recent data clearly demonstrate a non-genomic mode of action with a considerably more rapid onset of action within seconds to minutes [8]. It can be assumed that STC may exert rapidly anti-inflammatory effects and consequently diminish the local edematous reaction next to the bolus, especially in patients with an EoE without fibrostenotic phenotype. Additionally, according to Poiseuille's law, resistance to flow in a tubular structure is inversely proportional to the 4 th power of the radius, implying that already a minimal decrease in esophageal epithelial thickness is associated with considerable reduction in esophageal flow resistancy [9]. In view of these considerations, it is possible that an administration of BOT in the event of an EFI might promote resolution of bolus in patients with EoE.

The purpose of this report is to present the first experience using BOT as rescue treatment in clinically suspected, acute EFI. 


\section{Methods}

After the approval of BOT in Switzerland, physicians in the emergency department of the University Hospital of Zurich were instructed to directly administer one tablet of BOT $(1 \mathrm{mg})$ to patients presenting with clinically suspected EFI in the absence of any previously known stricture in the ER and to inform the gastroenterologist on call. Whether BOT was administered was at the discretion of the gastroenterologist on duty. Patients aged 18 years or older, admitted to the emergency department between March 2019 and June 2020 with suspected EFI at the moment of presentation, were eligible to receive Jorveza ${ }^{\circledR}$ as a pre-endoscopy EFI management without delaying endoscopy.

Patients gave written informed consent in order to use the medical information.

\section{Results}

In 15 months, a total of twelve patients with clinically suspected EFI presenting to the ER were reported to the gastroenterologist on call of which eight patients received BOT containing $1 \mathrm{mg}$ of Budesonide immediately after admission and thus were included in this analysis (Fig. 1). Mean age was 50.1 years (SD 11.4; 87.5\% male). Mean time from onset of symptoms of impaction to admission was $7.9 \mathrm{~h}$ (SD $7.3 \mathrm{~h}$ ), and from admission to complete resolution of symptoms or endoscopy $3.2 \mathrm{~h}$ (SD $2.2 \mathrm{~h}$ ), respectively. None of the patients had an established diagnosis of EoE prior to endoscopy (Table 1).

Among eight patients who received BOT, in 38\% the bolus could either not be observed in the esophagus at the time of endoscopy (2/8) or had complete resolution of symptoms so that scheduled emergent endoscopy was postponed (1/8). Endoscopic removal was necessary in five patients. In

Fig. 1 Flow chart

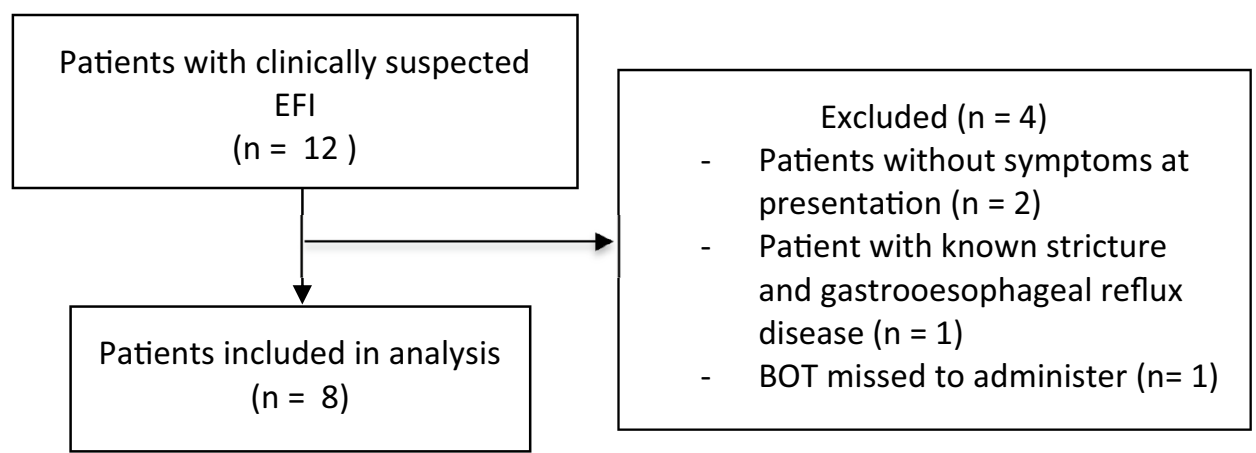

Table 1 Patient characteristics

\begin{tabular}{|c|c|c|c|c|c|c|c|c|c|}
\hline Patient & Gender & Age & $\begin{array}{l}\text { Duration from } \\
\text { Sx to admission } \\
\text { (min) }\end{array}$ & $\begin{array}{l}\text { Duration from } \\
\text { admission to } \\
\text { endoscopy/ } \\
\text { resolution of } \\
\text { symptoms (min) }\end{array}$ & Type of food & $\begin{array}{l}\text { Complete } \\
\text { dysphagia }\end{array}$ & Intubation & $\begin{array}{l}\text { Resolution of } \\
\text { bolus before } \\
\text { endoscopy }\end{array}$ & Diagnosis \\
\hline 1 & $\mathrm{~m}$ & 42 & 360 & 480 & Pizza & Yes & Yes & No & $\begin{array}{l}\text { EoE with } \\
\text { narrow-caliber } \\
\text { esophagus }\end{array}$ \\
\hline 2 & $\mathrm{w}$ & 71 & 1320 & 120 & Meat & No & No endoscopy & Yes & Loss to follow-up \\
\hline 3 & $\mathrm{~m}$ & 40 & 345 & 75 & Hazelnut & Yes & Yes & No & EoE \\
\hline 4 & $\mathrm{~m}$ & 53 & 960 & 120 & Meat & Yes & Yes & No & $\begin{array}{l}\text { EoE-like disease } \\
\text { with narrow- } \\
\text { caliber esopha- } \\
\text { gus }\end{array}$ \\
\hline 5 & $\mathrm{~m}$ & 48 & 60 & 180 & Shrimps & No & No & No & $\mathrm{EoE}$ \\
\hline 6 & $\mathrm{~m}$ & 49 & 400 & 80 & Meat & Yes & Yes & Yes & $\mathrm{EoE}$ \\
\hline 7 & $\mathrm{~m}$ & 37 & 285 & 315 & Meat & Yes & Yes & Yes & $\mathrm{EoE}$ \\
\hline 8 & $\mathrm{~m}$ & 61 & 120 & 180 & Meat & Yes & Yes & No & $\begin{array}{l}\text { Reflux esophagi- } \\
\text { tis with peptic } \\
\text { stricture }\end{array}$ \\
\hline
\end{tabular}


all patients with a documented stricture or narrow-caliber esophagus (3/8), persistent EFI was observed at endoscopy, requiring endoscopic removal. Among patients with a resolution of EFI before endoscopy, the type of food causing the bolus was in all cases meat. A clinico-histologic diagnosis of EoE was established in 75\% (six out of eight patients).

\section{Discussion}

Here we describe the first experience with BOT as medical rescue treatment in patients with clinically suspected EFI. In approximately $40 \%$ of patients with clinically suspected EFI the impaction has resolved after the administration of BOT.

However, due to the small sample size and the lack of a control group this brief report has several important limitations and the findings cannot provide any robust evidence on the efficacy of BOT in this indication. Nevertheless, the following considerations are arguments that STCs administered immediately upon presentation in the ER, before emergent endoscopy, might have the potential to promote resolution of EFI in EoE: firstly, the nearly $40 \%$ resolution rate in our case series is considerably higher compared to a study including $645 \mathrm{EFI}$, where a spontaneous resolution of impaction was found only in $16.7 \%$ [2], but similar to most used pharmacologic therapies in case of EFI [3]. Secondly, the time period between onset of EFI-indicating symptoms and ER admission was rather long; therefore, minimizing the probability of spontaneous resolution. Thirdly, in line with Poiseuille's law only very subtle reductions of esophageal epithelial thickness (and thus esophageal lumen diameter) are associated with considerable reductions of flow resistance, potentially being sufficient to enable spontaneous bolus relief also in patients with a mixed fibrotic/inflammatory EoE phenotype.

Although efficacy of BOT does not appear to be superior to other pharmacologic therapies, the administration with an oral dissolution of a very small tablet (size $7.1 \mathrm{~mm}$ diameter) harbors almost no risk even in the emergency setting of an EFI. Of note, this intervention does not interfere with the established management of EFI; it has led neither to a delay nor to increased technical difficulties of the subsequent endoscopic procedure.

In conclusion, keeping in mind that emergency endoscopic procedures in EFI may not be promptly available in several institutions globally and harbor several substantial risks [3], and that the above mentioned medical intervention is almost riskless and has the potential to resolve food impactions, we believe that this approach is worth for further evaluation. A larger randomized placebo-controlled trial will provide definite clarification of BOTs efficacy in this indication.
Author Contributions PS conception and design of the study, drafting the article, approved the final version. TG design of the study, critical revision, and approved the final version. AT design of the study, critical revision, and approved the final version. DIK design of the study, critical revision, and approved the final version. AS design of the study, critical revision, and approved the final version. LB concept and design of the study, critical revision, and approved the final version.

Funding Open Access funding provided by Universität Zürich. No financial support.

\section{Declarations}

Conflict of interest PS received consulting fees from Pfizer, Takeda and Janssen-Cilag and travel support from Falk, UCB and Pfizer. TG has consulting contracts with Sanofi-Regeneron and Falk Pharma $\mathrm{GmbH}$, received travel grants from Falk Pharma GmbH and Vifor, and an unrestricted research grant from Novartis. AT has no conflict of interest. DIK has no conflict of interest. AS reports receiving consulting fees from Allakos, AstraZeneca, EsoCap, Dr. Falk Pharma, Gossamer, GSK, Receptos-Celgene and Regeneron-Sanofi. LB received consulting fees and/or speaker fees and/or research grants from Dr. Falk Pharma, GmbH, Germany, Vifor AG, Switzerland, Esocap AG, Switzerland, Sanofi-Aventis AG, Switzerland and Calypso Biotech SA.

Open Access This article is licensed under a Creative Commons Attribution 4.0 International License, which permits use, sharing, adaptation, distribution and reproduction in any medium or format, as long as you give appropriate credit to the original author(s) and the source, provide a link to the Creative Commons licence, and indicate if changes were made. The images or other third party material in this article are included in the article's Creative Commons licence, unless indicated otherwise in a credit line to the material. If material is not included in the article's Creative Commons licence and your intended use is not permitted by statutory regulation or exceeds the permitted use, you will need to obtain permission directly from the copyright holder. To view a copy of this licence, visit http://creativecommons.org/licenses/by/4.0/.

\section{References}

1. Sengupta N, Tapper EB, Corban C, Sommers T, Leffler DA, Lembo AJ. The clinical predictors of aetiology and complications among 173 patients presenting to the Emergency Department with oesophageal food bolus impaction from 2004-2014. Aliment Pharmacol Ther. 2015;42(1):91-8. https://doi.org/10. 1111/apt.13237.

2. Schupack DA, Lenz CJ, Geno DM, Tholen CJ, Leggett CL, Katzka DA, Alexander JA. The evolution of treatment and complications of esophageal food impaction. U Eur Gastroenterol J. 2019;7(4):548-56. https://doi.org/10.1177/2050640619836052.

3. Peksa GD, DeMott JM, Slocum GW, Burkins J, Gottlieb M. Glucagon for relief of acute esophageal foreign bodies and food impactions: a systematic review and meta-analysis. Pharmacotherapy. 2019;39(4):463-72. https://doi.org/10.1002/phar.2236.

4. Willenbring BA, Schnitker CK, Stellpflug SJ. Oral nitroglycerin solution may be effective for esophageal food impaction. J Emerg Med. 2018;54(5):678-80. https://doi.org/10.1016/j.jemermed. 2018.01.024.

5. Lucendo AJ, Miehlke S, Schlag C, Vieth M, von Arnim U, Molina-Infante J, Hartmann D, Bredenoord AJ, Ciriza de Los Rios C, Schubert S, Bruckner S, Madisch A, Hayat J, Tack J, Attwood 
S, Mueller R, Greinwald R, Schoepfer A, Straumann A, International EOSSG. Efficacy of budesonide orodispersible tablets as induction therapy for eosinophilic esophagitis in a randomized placebo-controlled trial. Gastroenterology. 2019;157(1):74-86 e15. https://doi.org/10.1053/j.gastro.2019.03.025

6. Straumann A, Lucendo AJ, Miehlke S, Vieth M, Schlag C, Biedermann L, Vaquero CS, Ciriza de Los Rios C, Schmoecker C, Madisch A, Hruz P, Hayat J, von Arnim U, Bredenoord AJ, Schubert S, Mueller R, Greinwald R, Schoepfer A, Attwood S, International EOSSG. Budesonide orodispersible tablets maintain remission in a randomized, placebo-controlled trial of patients with eosinophilic esophagitis. Gastroenterology. 2020. https://doi. org/10.1053/j.gastro.2020.07.039

7. Gibson PG, Saltos N, Fakes K. Acute anti-inflammatory effects of inhaled budesonide in asthma: a randomized controlled trial. Am J Respir Crit Care Med. 2001;163(1):32-6. https://doi.org/10. 1164/ajrccm.163.1.9807061.

8. Panettieri RA, Schaafsma D, Amrani Y, Koziol-White C, Ostrom R, Tliba O. Non-genomic effects of glucocorticoids: an updated view. Trends Pharmacol Sci. 2019;40(1):38-49. https://doi.org/ 10.1016/j.tips.2018.11.002.
9. Markowitz JE, Clayton SB. Eosinophilic esophagitis in children and adults. Gastrointest Endosc Clin N Am. 2018;28(1):59-75. https://doi.org/10.1016/j.giec.2017.07.004.

Publisher's Note Springer Nature remains neutral with regard to jurisdictional claims in published maps and institutional affiliations.

Philipp Schreiner MD

Thomas Greuter MD

Aurora Tatu MD

Dagmar I. Keller MD

Alex Straumann MD

Luc Biedermann MD 